Ophthalmologe 2022 $\cdot 119$ (Suppl 2):S154

https://doi.org/10.1007/s00347-022-01582-x

Online publiziert: 27. Januar 2022

() The Author(s), under exclusive licence to

Springer Medizin Verlag GmbH, ein Teil von

Springer Nature 2022

\section{Erratum zu: UV-Schutz-Bündnis in Deutschland - Zeitstrahl der inhaltlichen Entwicklung}

Redaktion „Der Ophthalmologe“

Springer Medizin Verlag GmbH, Heidelberg, Deutschland

\section{Erratum zu:}

Ophthalmologe 2021

https://doi.org/10.1007/s00347-021-

01545-8

In den XML-Daten des ursprünglichen Artikels wurden die vier Mitglieder des UVSchutz-Bündnisses Claas Ulrich, Henriette Bunde, Vinodh Kakkassery und Claudine Strehl versehentlich nicht genannt. Die XML-Daten wurden nachträglich korrigiert.

Wir bitten, die Korrektur zu beachten und den Fehler zu entschuldigen.

Die Redaktion

\section{Korrespondenzadresse}

Redaktion „Der Ophthalmologe“

Springer Medizin Verlag $\mathrm{GmbH}$

Heidelberg, Deutschland

michal.meyerzutittingdorf@springer.com
Die Online-Version des Originalartikels ist unter https://doi.org/10.1007/s00347-021-01545-8 zu finden. 